\title{
Manganese(II) in Tetrahedral Halide Environment: Factors Governing Bright Green Luminescence
}

\author{
Viktoriia Morad, ${ }^{\dagger, \ddagger}$ Ihor Cherniukh, ${ }^{\dagger, \ddagger}$ Lena Pöttschacher, ${ }^{\dagger}$ Yevhen Shynkarenko, ${ }^{\dagger, \ddagger}$ Sergii Yakunin, ${ }^{\dagger, \ddagger \Subset}$ \\ and Maksym V. Kovalenko*,†, \\ ${ }^{\dagger}$ Laboratory of Inorganic Chemistry, Department of Chemistry and Applied Bioscience, ETH Zürich, Vladimir Prelog Weg 1, \\ CH-8093 Zürich, Switzerland \\ ${ }^{\ddagger}$ Laboratory for Thin Films and Photovoltaics, Empa-Swiss Federal Laboratories for Materials Science and Technology, \\ Überlandstrasse 129, CH-8600 Dübendorf, Switzerland
}

\section{Supporting Information}

\begin{abstract}
Finding narrow-band light emitters for the visible spectral region remains an immense challenge. Such phosphors are in great demand for solid-state lighting and display application. In this context, green luminescence from tetrahedrally coordinated $\mathrm{Mn}$ (II) is an attractive research direction. While the oxide-ligand environment had been studied for decades, much less systematic efforts have been undertaken with regard to halide coordination, especially in the form of fully inorganic halide matrixes. In this study, we synthesized a series of hybrid organic-inorganic $\mathrm{Mn}$ (II) halides as well as a range of fully inorganic $\mathrm{Zn}$ halide hosts (chlorides, bromides, iodides) doped with $\mathrm{Mn}$ (II). In the latter, tetrahedral coordination is attained via substitutional doping owing to the

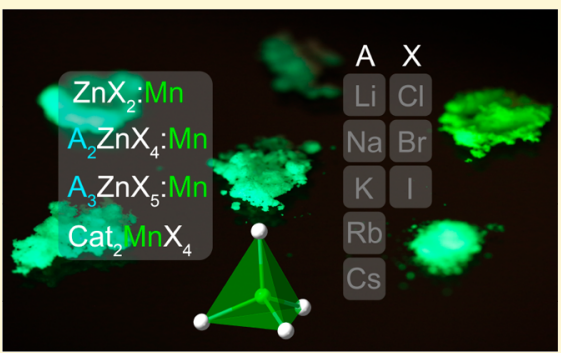
tetrahedral symmetry of $\mathrm{Zn}$ sites. We find that the choice of the halide as well as subtle details of the crystal structure profoundly govern the photoluminescence peak positions (500-550 nm range) and emission line widths (40-60 nm) as well as radiative lifetimes (shorter for iodides) through the altered ligand-field effects and degrees of spin-orbit coupling. The photoluminescence quantum yields were as high as 70-90\%. The major hurdle for the practical use of these compounds lies in their low absorption coefficients in the blue spectral regions.
\end{abstract}

\section{INTRODUCTION}

Light-emitting materials have a broad spectrum of applications including solid-state lighting, flat panel display technologies, optical data storage, radiation detection, and photovoltaics. ${ }^{1-5}$ Narrow-band green-emitting phosphors with an emission peak around 520-535 $\mathrm{nm}$ are central for displays and solid-state lighting technologies. ${ }^{6}$ In recent years, cadmium(II) chalcogenide ( $\mathrm{Se}, \mathrm{S}$, or $\mathrm{Te}$ ) nanocrystals (NCs), exhibiting photoluminescence $(\mathrm{PL})$ full width at half maxima (fwhm) of $<30$ $\mathrm{nm}$ and PL quantum yields (QYs) of above $95 \%$, have been used as phosphors in backlighting of displays. ${ }^{7}$ Limited RoHS compliance and steadily decreasing public and commercial acceptance of heavy-metal-containing materials motivated commercial deployment of environmentally benign indium phosphide $\mathrm{NCs}^{8}$ in spite of their considerably broader emission line width $(38-40 \mathrm{~nm})$ and lower stability. An emerging alternative are highly luminescent lead halide perovskite NCs (fwhm $\approx 20 \mathrm{~nm}$ at $520-530 \mathrm{~nm}$ PL peak), ${ }^{9}$ whose practical potential still needs to be thoroughly examined. Thus far, the most successful commercial phosphors are still those based on emissive rare-earth or transition-metal ions embedded into a stable crystalline host. ${ }^{6,10}$ In particular, $\beta$-SiAlON:Eu ${ }^{2+}(\mathrm{PL}$ peak at $535 \mathrm{~nm}, \mathrm{fwhm} \approx 50 \mathrm{~nm})$ is used in commercial LCDs, ${ }^{11}$ while other $\mathrm{Eu}^{2+}$-based compounds comprise a subject of continued research efforts. ${ }^{12,13}$
Tetrahedrally coordinated $\mathrm{Mn}$ (II) exhibits green emission and is thus of interest for engineering solid-state phosphors. The emission of $\mathrm{Mn}(\mathrm{II})$ and $\mathrm{Mn}(\mathrm{IV})$ in octahedral $\left(O_{h}\right)$ and tetrahedral $\left(T_{d}\right)$ crystal fields has been studied for decades. ${ }^{14,15}$ For instance, red-emissive $\mathrm{K}_{2} \mathrm{SiF}_{6}: \mathrm{Mn}^{4+}$ (octahedral coordination) has become a commercial red phosphor for white lightemitting diodes. ${ }^{16}$ In a tetrahedral field $\left(T_{d}\right)$ of oxide ligands, ${ }^{17,18}$ green emission of $\mathrm{Mn}(\mathrm{II})$ is characterized by a fwhm below $45 \mathrm{~nm}$ and can be as narrow as $26 \mathrm{~nm}^{18}$ However, the main drawback of the oxide field is slow emission decay, typically 4-6 ms. The emission is due to intra-atomic transitions within the split energy states. ${ }^{19,20}$ The magnitude of the splitting is quantified by $B, C$, and $\Delta$ parameters. The $B$ and $C$ parameters relate to the Coloumb (electron-electron) repulsion, and $\Delta$ quantifies the strength of the crystal field (CF). In addition, the so-called nephelauxetic parameter $\beta=$ $B^{\prime} / B$, where $B$ and $B^{\prime}$ are the parameters for a free d-metal ion and an ion in the complex, respectively, is often used to estimate the covalency of the metal-ligand bond. The nephelauxetic effect describes the influence of the ligand on the d-orbitals expansion upon ligation. Greater orbital expansion reduces the Coulomb repulsion. The variation of

Received: September 14, 2019

Revised: November 14, 2019

Published: November 15, 2019 
the $\Delta$ for different ligands is known as the spectrochemical series, whereas the nephelauxetic series reflects the magnitude of $B$ parameter reduction compared to a free ion. Scheme 1

Scheme 1. Energy States Splitting and Optical Transitions in Tetrahedrally Coordinated $\mathrm{Mn}^{2+}$ Ion

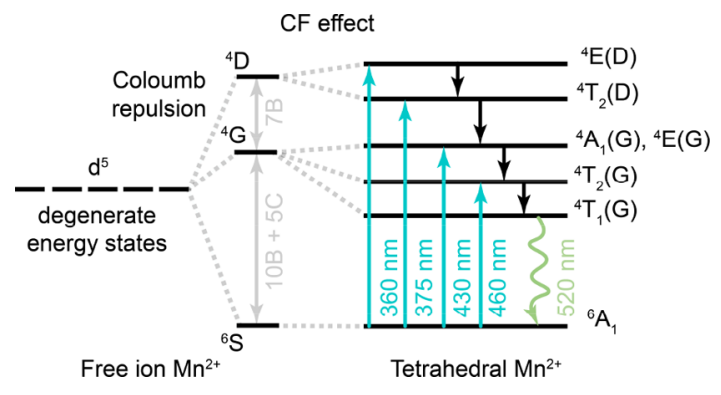

and Table S1 illustrate the energy states splitting for $\mathrm{Mn}$ in $T_{d}$ environment. ${ }^{21,22}$ A spectrally narrow, i.e., $25-60 \mathrm{~nm}$ in fwhm, green emission peaked at $500-550 \mathrm{~nm}$ originates from the lowest ${ }^{4} \mathrm{~T}_{1} \rightarrow{ }^{6} \mathrm{~A}_{1}$ transition. The excitation spectra in the blue and near-ultraviolet (near-UV) features several bands, corresponding to two groups of transitions: ${ }^{6} \mathrm{~A}_{1} \rightarrow{ }^{4} \mathrm{G}$ and ${ }^{6} \mathrm{~A}_{1} \rightarrow{ }^{4} \mathrm{D}$. In addition, interatomic $\mathrm{Mn}-\mathrm{Mn}$ interaction can further modify the energy states. The $\mathrm{Mn}$ (II) emission in the octahedral environment is known to be in the red region, foremost due to the weaker ligand field, as compared to the $T_{d}$ coordination. In addition, the distance between $\mathrm{O}_{h}-\mathrm{Mn}$ (II) atoms had been reported to adjust the PL peak position in the orange-red region. ${ }^{23}$ The $\mathrm{d}-\mathrm{d}$ transition of $\mathrm{Mn}^{2+}$ in the centrosymmetric $O_{h}$ is, however, forbidden by the Laporte selection rule, making the observed luminescence very weak. In noncentrosymmetric complexes the rule above is nonapplicable, rendering a more efficient absorption and emission by $\mathrm{Mn}^{2+}$. In this study, we cast our attention toward $\mathrm{Mn}^{2+}$ green emission in a $T_{d}$ halide environment (chloride, bromide, and iodide) to unveil the factors governing the PL characteristics.

We pursue two approaches for realizing $\mathrm{Mn}$ (II) green emission in a $T_{d}$ field of halide atoms: (a) structurally zerodimensional hybrid organic-inorganic manganese(II) tetrahalides or (b) doping of hosts with $T_{d}$ centers. The organicinorganic manganese(II) tetrahalides (case a) comprise isolated $\mathrm{MnX}_{4}$ anions surrounded by the bulky organic cations. Although such hybrid compounds have been known for several decades, ${ }^{20}$ they have recently regained popularity due to high
PLQY of up to $90 \%,{ }^{24}$ spectrally narrow emission ( fwhm $\approx 50$ $\mathrm{nm}$ ), and demonstration of electroluminescence with a high external quantum efficiency of up to $10 \% .{ }^{25,26}$ In some of these hybrids, triboluminescence (i.e., luminescence under mechanical stress) had been reported as well. ${ }^{27}$ Case b is represented by either a fully inorganic matrix of binary zinc halides $\left(\mathrm{ZnBr}_{2}\right.$, $\mathrm{ZnI}_{2}$ ) or ternary alkali zinc halides doped with $\mathrm{Mn}^{2+}$ (Figure 1). Interestingly, despite the simplicity of the idea, $\mathrm{ZnX}_{2}$ had thus far not been reported as a host for $\mathrm{Mn}^{2+}$. For comparison, emission of $\mathrm{Mn}$ (II) in $\mathrm{MgBr}_{2}$ matrix stems from the octahedral coordination and hence is in the red region. ${ }^{28}$ Both $\mathrm{ZnBr}_{2}$ and $\mathrm{ZnI}_{2}$ have the same structure comprising groups of four cornersharing $\mathrm{ZnX}_{4}$ tetrahedra, extending in three dimensions. Although $\mathrm{Mn}(\mathrm{II})$ ions are larger than $\mathrm{Zn}^{2+}$ ions ( 0.66 vs 0.6 $\AA$ ), they occupy exclusively $T_{d}$ sites as they are not large enough for the stable coordination in $\mathrm{O}_{h}$ voids. Zerodimensional alkali zinc halides, wherein $\mathrm{ZnX}_{4}$ units are disconnected, can be prepared in two common stoichiometries, $\mathrm{A}_{2} \mathrm{ZnX}_{4}$ and $\mathrm{A}_{3} \mathrm{ZnX}_{5}(\mathrm{~A}=\mathrm{Li}, \mathrm{Na}, \mathrm{K}, \mathrm{Rb}, \mathrm{Cs}) .{ }^{29-37}$ There are very few reports upon which one can try to build the comprehension of the factors governing the PL characteristics of these hybrids. ${ }^{20,38}$ No reports on green emission from $\mathrm{Mn}$ in fully inorganic halide hosts could be identified. Furthermore, Mn doping of such matrices has remained rather unexplored; we found only one report on electron paramagnetic resonance measurements of manganese in $\mathrm{Cs}_{2} \mathrm{ZnBr}_{4}$ and $\mathrm{Rb}_{3} \mathrm{ZnBr}_{5}{ }^{39}$ and a recent report on the synthesis and optical properties of $\mathrm{Cs}_{3} \mathrm{MnBr}_{5}$, which is isostructural to $\mathrm{Cs}_{3} \mathrm{ZnBr}_{5}$. ${ }^{40}$

\section{EXPERIMENTAL SECTION}

The list of chemicals is available in the Supporting Information.

Synthesis of Organic-Inorganic Hybrids. Hybrid phosphors were obtained from $\mathrm{MnX}_{2}$ and organic cation halide precursor solutions in ethanol, methanol, or dimethylformamide. In addition, some compounds were obtained in a reaction of $\mathrm{MnCO}_{3}$ with organic cation in aqueous hydrohalic acids. For example, for the preparation of $\mathrm{Bmpip}_{2} \mathrm{MnCl}_{4}, \mathrm{BmpipCl}\left(0.4 \mathrm{mmol}, 0.0767 \mathrm{~g}\right.$ ) and $\mathrm{MnCl}_{2}(0.2$ mmol, $0.0252 \mathrm{~g}$ ) were dissolved in $1.5 \mathrm{~mL}$ of $\mathrm{MeOH}$ with stirring. The solution was filtered through a $0.2 \mu \mathrm{m}$ PTFE filter. For singlecrystal growth, the crude solution was either slowly concentrated at 50 ${ }^{\circ} \mathrm{C}$ or placed into an antisolvent evaporation chamber with dichloromethane. In a typical synthesis from a hydrohalic acid, $\mathrm{N}$ benzyl- $N, N, N$-trimethyl chloride $\left(1 \mathrm{mmol}, 0.1875 \mathrm{~g}\right.$ ) and $\mathrm{MnCO}_{3}$ $(0.5 \mathrm{mmol}, 0.0575 \mathrm{~g})$ were dissolved in aqueous $\mathrm{HCl}(6 \mathrm{mmol}, 0.53$ $\mathrm{mL}$ ) at $70^{\circ} \mathrm{C}$. Single crystals were grown by slow evaporation of the filtered precursor solution at room temperature.

Synthesis of Fully Inorganic Mn-Doped Hosts. $\mathrm{Na}_{2} \mathrm{ZnBr}_{4}$ and $\mathrm{Li}_{2} \mathrm{ZnBr}_{4}$ were prepared as follows. Dry $\mathrm{ABr}(\mathrm{A}=\mathrm{Na}$ or $\mathrm{Li})$ and
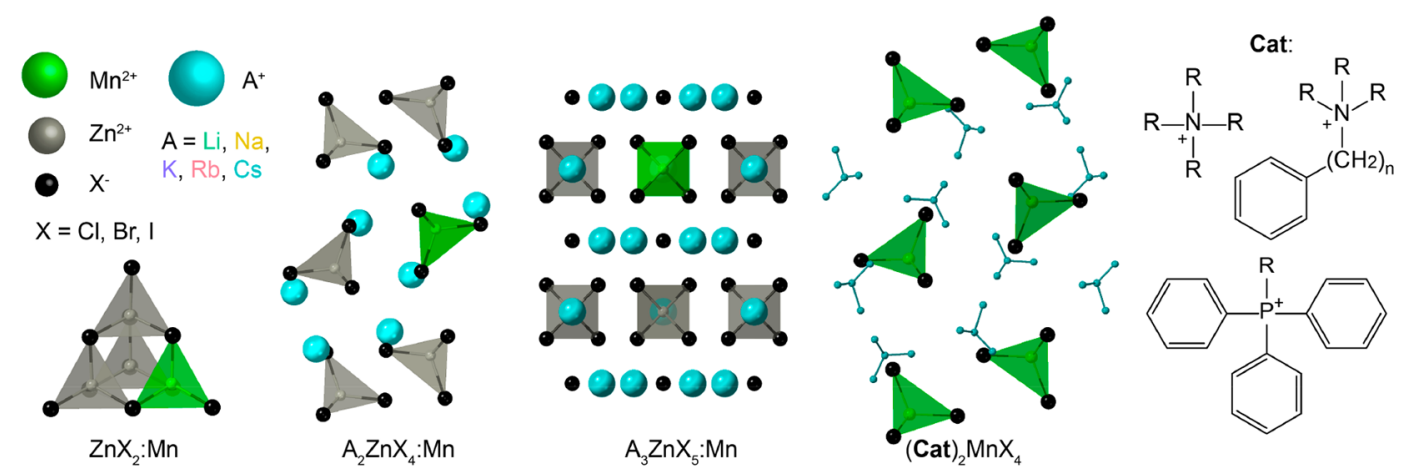

Figure 1. Various compounds, studied in this work, featuring tetrahedral coordination of $\mathrm{Mn}(\mathrm{II})$. Mn ions are introduced either in the form of dopant $\left(\mathrm{ZnX}_{2}, \mathrm{~A}_{2} \mathrm{ZnX}_{4}, \mathrm{~A}_{3} \mathrm{ZnX}_{5}\right)$ or as anion in organic-inorganic hybrids $(\mathrm{Cat})_{2} \mathrm{MnX}_{4}$. 

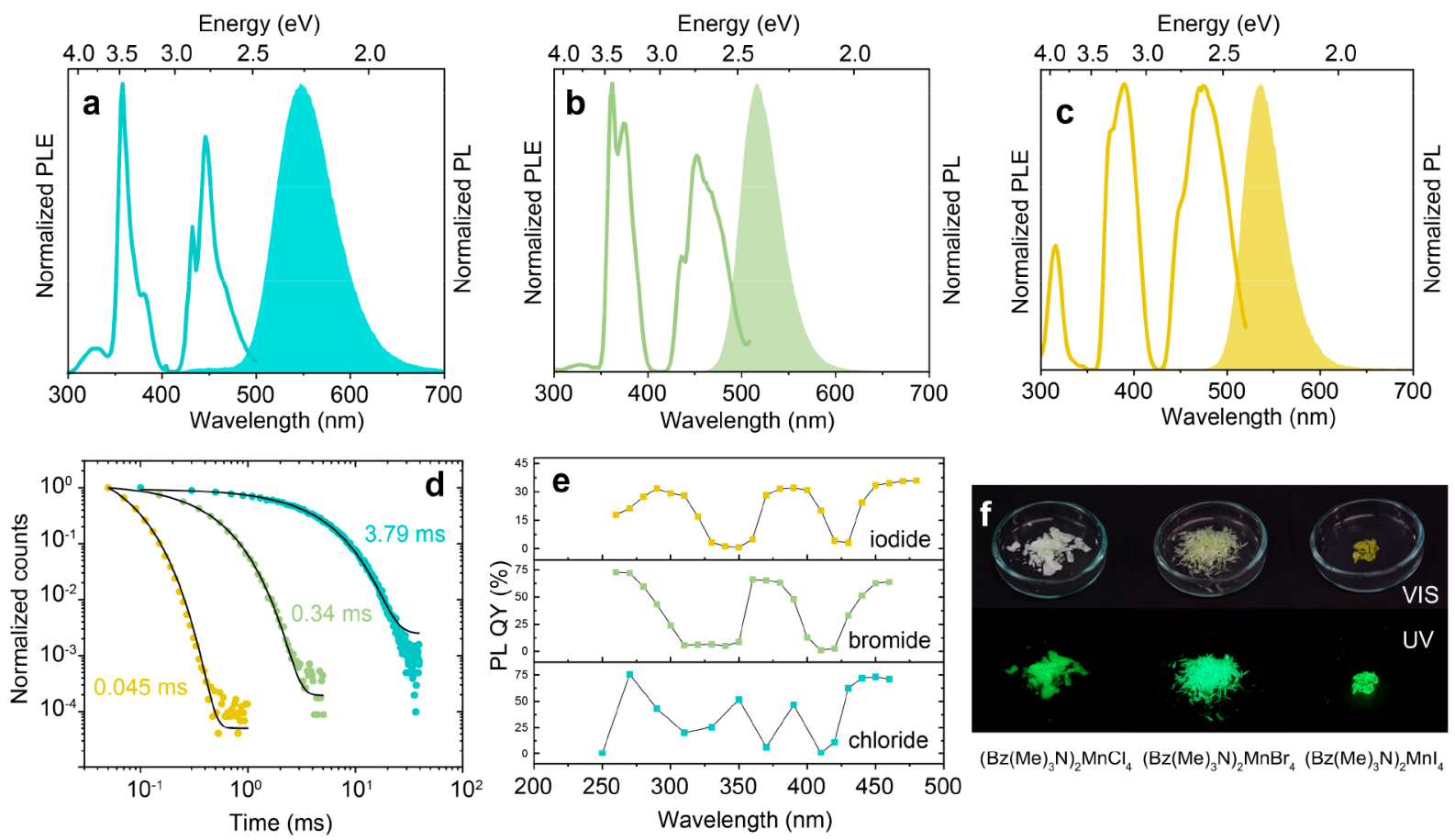

Figure 2. (a-c) PLE (empty) and PL (shaded, exc. $360 \mathrm{~nm}$ ) of three hybrid compounds: $\left(\mathrm{Bz}(\mathrm{Me})_{3} \mathrm{~N}\right)_{2} \mathrm{MnX} \mathrm{X}_{4}(\mathrm{X}=\mathrm{Cl}, \mathrm{Br}, \mathrm{I})$. (d) Emission decay curves for $\left(\mathrm{Bz}(\mathrm{Me})_{3} \mathrm{~N}\right)_{2} \mathrm{MnX}_{4}(\mathrm{X}=\mathrm{Cl}, \mathrm{Br}, \mathrm{I})$. (e) PLQY dependence on the excitation wavelength for $\left(\mathrm{Bz}(\mathrm{Me})_{3} \mathrm{~N}\right)_{2} \mathrm{MnX}{ }_{4}(\mathrm{X}=\mathrm{Cl}, \mathrm{Br}, \mathrm{I})$. $(\mathrm{f})$ Photographs of $\left(\mathrm{Bz}(\mathrm{Me})_{3} \mathrm{~N}\right)_{2} \mathrm{MnX}_{4}$ under visible light and $\mathrm{UV}$ excitation $(365 \mathrm{~nm})$.

$\mathrm{ZnBr}_{2}$ mixed at a molar ratio of 2:1 was loaded in a Pyrex ampule and sealed under vacuum. The ampule was placed in a quartz tube and heated to the melting point (326 and $347{ }^{\circ} \mathrm{C}$ for $\mathrm{Li}_{2} \mathrm{ZnBr}_{4}$ and $\mathrm{Na}_{2} \mathrm{ZnBr}_{4}$, respectively) at a heating rate of $50{ }^{\circ} \mathrm{C} / \mathrm{h}$. Samples were kept at this temperature for $12 \mathrm{~h}$ and cooled to room temperature at a rate of $10{ }^{\circ} \mathrm{C} / \mathrm{h}$. For other ternary halides, samples were kept $10-20$ ${ }^{\circ} \mathrm{C}$ above the melting point for $1-2 \mathrm{~h}$ and then cooled to room temperature at a rate of $50{ }^{\circ} \mathrm{C} / \mathrm{h}$.

Characterization. Powder X-ray diffraction (XRD) patterns were collected in transmission (Debye-Scherrer geometry) with a STADI $\mathrm{P}$ diffractometer (STOE Cie $\mathrm{GmbH}$ ), equipped with a silicon strip MYTHEN 1K Detector (Fa. DECTRIS) with a curved Ge (111)Monochromator $(\mathrm{Cu} \mathrm{K} \alpha 1=1.54056 \AA)$. For the measurement, a grounded powder was placed between the adhesive tape. Singlecrystal XRD measurements were conducted on Oxford Xcalibur $S$ diffractometer equipped with a Sapphire 3 CCD detector and a molybdenum (Mo $\mathrm{K} \alpha=0.71073 \AA$ ) sealed tube as an X-ray source. Crystals were tip mounted on a micromount with paraffin oil. The data were processed with Oxford Diffraction CrysAlis Pro software; structure solution and refinement were performed with SHELXS and SHELXL, respectively, imbedded in the Olex2 package. ${ }^{41,42}$ The crystal structure of the synthesized compound was solved with direct methods, light elements $(\mathrm{C}, \mathrm{N})$ were located in the difference Fourier map, most of the positions of the cations were refined as rigid groups, and hydrogen atoms were placed at calculated positions.

Photoluminescence emission and excitation steady-state spectra were recorded with a FluoroMax4-Plus-P (Horiba Jobin Yvon) equipped with a $150 \mathrm{~W}$ Xe lamp. Absolute quantum yields of the powders were measured using a Quantaurus-QY (Hamamatsu) spectrometer with an integrating sphere in a quartz Petri dish. The relative uncertainty of the PLQY measurement is $\pm 3 \%$.

Photoluminescence decay was measured with a FluoroMax4-Plus-P equipped with a pulsed Xe lamp ( $3 \mu \mathrm{s})$. Decay curves were measured as a PL peak intensity over time. The temporal window size was $5 \mu \mathrm{s}$; each data point is accumulated over 100 lamp flashes.

Attenuation coefficient estimation was obtained from the transmission spectra of a single crystal through two parallel facets, recorded on a Jasco V500 spectrometer. The crystal was positioned into an opaque diaphragm with a hole of the crystal size. The diaphragms were used to calibrate baselines of the spectrometer according to the sample's sizes. Reflection and scattering losses were taken into account by the measurement of specular and diffuse reflection spectra in the integrating sphere with an aluminum foil of the corresponding size as a reference. The spectral attenuation coefficient $\mu_{\lambda}$ of a crystal with dimension $l$ was estimated from the optical density $\tau$ according to the equation

$$
\mu_{\lambda}=\tau / l,\left[\mathrm{~cm}^{-1}\right]
$$

To analyze $\mathrm{Mn}-\mathrm{Br}$ distances in the host lattice of ternary metal halides, density functional theory (DFT) was used as implemented in the Vienna Ab Initio Simulation Package (VASP) code. The projector augmented wave (PAW) potentials for atoms were used. For the generalized gradient approximation (GGA), the Perdew-BurkeErnzerhof exchange-correlation functional (PBE) was used. ${ }^{43-45} \mathrm{~A}$ 112-atom supercell $(2 \times 2 \times 1)$ of each compound containing one $\mathrm{Mn}$ on $\mathrm{Zn}$ site was used for the calculations. Atomic positions were optimized while keeping the lattice parameters constant until the forces on atoms were smaller than $0.01 \mathrm{eV} / \mathrm{A}$. A gamma-centered automatic $k$-point mesh with $2 \times 2 \times 2$ density was used.

\section{RESULTS AND DISCUSSION}

Organic-Inorganic Hybrids. Organic-inorganic Mn(II) halides can be prepared from the corresponding aqueous hydrohalic acid solution of manganese halide and organic cation or from the solution of cation halide and manganese halide in polar organic solvents (methanol, ethanol, acetonitrile, $N$-methylformamide, $N, N$-demithylformamide, dimethyl sulfoxide). To display the trends in emission properties, we have selected three manganese(II) halide complexes with 1benzyl-1-trimethylammonium $\left(\mathrm{Bz}(\mathrm{Me})_{3} \mathrm{~N}\right)^{+}$cation (Figure 2). This cation was chosen for its bulkiness and anticipating that $\pi-\pi$ stacking aids in crystallization. The cation bulkiness favors the crystallization of manganese in isolated $\mathrm{MnX}_{4}$ units. $\left(\mathrm{Bz}(\mathrm{Me})_{3} \mathrm{~N}\right)_{2} \mathrm{MnBr}_{4}$ and $\left(\mathrm{Bz}(\mathrm{Me})_{3} \mathrm{~N}\right)_{2} \mathrm{MnI}_{4}$ are isostructural 
Table 1. Optical Properties (peak position, FWHM, PLQY) of the Organic-Inorganic Manganese(II) Tetrahalide Hybrids ${ }^{a}$

\begin{tabular}{|c|c|c|c|c|c|c|}
\hline cation & halide & peak position, $\mathrm{nm}$ & fwhm, nm & fwhm, meV & PLQY, ${ }^{b}$ & $\mathrm{E}\left[{ }^{4} \mathrm{~T}_{2}\right]-\mathrm{E}\left[{ }^{4} \mathrm{~T}_{1}\right], \mathrm{meV}$ \\
\hline $\mathrm{Et}_{4} \mathrm{~N}$ & $\mathrm{Cl}$ & 518 & 53.1 & 246 & 75 & 36 \\
\hline$n-\mathrm{Pr}_{4} \mathrm{~N}$ & & 512 & 49.8 & 236 & 81 & 35 \\
\hline $\mathrm{Bz}(n-\mathrm{Bu})_{3} \mathrm{~N}$ & & 522 & 57.5 & 262 & 60 & 39 \\
\hline $\mathrm{Ph}(\mathrm{Me})_{3} \mathrm{~N}$ & & 522 & 55.1 & 251 & 89 & 36 \\
\hline $\mathrm{Ph}_{4} \mathrm{P}$ & & 517 & 55.8 & 260 & $\mathrm{~N} / \mathrm{A}$ & 39 \\
\hline $\mathrm{Et}(\mathrm{Ph})_{3} \mathrm{P}$ & & 520 & 55.8 & 257 & 66 & 38 \\
\hline $\mathrm{Bz}(\mathrm{Me})_{3} \mathrm{~N}$ & & 547 & 71.8 & 299 & 78 & 51 \\
\hline$\left(\mathrm{PPh}_{3}\right)_{2}=\mathrm{N}$ & & 544 & 62.4 & 262 & $\mathrm{~N} / \mathrm{A}$ & 51 \\
\hline $\mathrm{Et}_{4} \mathrm{~N}$ & $\mathrm{Br}$ & 516 & 49.1 & 229 & 86 & 34 \\
\hline$n-\operatorname{Pr}_{4} \mathrm{~N}$ & & 511 & 47.8 & 227 & $\mathrm{~N} / \mathrm{A}$ & 33 \\
\hline $\mathrm{Bz}(n-\mathrm{Bu})_{3} \mathrm{~N}$ & & 520 & 53.5 & 246 & 68 & 36 \\
\hline $\mathrm{Ph}(\mathrm{Me})_{3} \mathrm{~N}$ & & 520 & 49.2 & 226 & 76 & 35 \\
\hline $\mathrm{Ph}_{4} \mathrm{P}$ & & 516 & 48.3 & 225 & $\mathrm{~N} / \mathrm{A}$ & 34 \\
\hline $\mathrm{Me}(\mathrm{Ph})_{3} \mathrm{P}$ & & 507 & 40.5 & 196 & 74 & 30 \\
\hline $\mathrm{Et}(\mathrm{Ph})_{3} \mathrm{P}$ & & 510 & 43.6 & 208 & 45 & 32 \\
\hline $\mathrm{Bz}(\mathrm{Me})_{3} \mathrm{~N}$ & & 516 & 48.7 & 227 & 63 & 34 \\
\hline $\mathrm{K}[$ crypt-222] & & 504 & 39.4 & 193 & N/A & 31 \\
\hline $\mathrm{Et}_{4} \mathrm{~N}$ & I & 535 & 52 & 226 & 62 & 32 \\
\hline$n-\mathrm{Pr}_{4} \mathrm{~N}$ & & 531 & 54 & 238 & $\mathrm{~N} / \mathrm{A}$ & 31 \\
\hline $\mathrm{Ph}(\mathrm{Me})_{3} \mathrm{~N}$ & & 540 & 55.3 & 236 & $\mathrm{~N} / \mathrm{A}$ & 31 \\
\hline $\mathrm{Bz}(\mathrm{Me})_{3} \mathrm{~N}$ & & 537 & 49.8 & 215 & 33 & 30 \\
\hline
\end{tabular}

${ }^{a}$ The strength of the crystal field is reflected in the difference between optical bands $\mathrm{E}\left[{ }^{4} \mathrm{~T}_{2}\right]$ and $\mathrm{E}\left[{ }^{6} \mathrm{~A}_{1}\right] .{ }^{b} \mathrm{PLQY}$ measured with $450 \mathrm{~nm}$ excitation.

and feature one asymmetric unit of $\mathrm{MnX}_{4}$, whereas (Bz$\left.(\mathrm{Me})_{3} \mathrm{~N}\right)_{2} \mathrm{MnCl}_{4}$ comprises two inequivalent $\mathrm{MnCl}_{4}$ units. The PL excitation (PLE) spectra of all three compounds contain bands that are corresponding to the transitions described above (Scheme 1). In the region between 300 and $500 \mathrm{~nm}$ there are two distinct groups of bands, corresponding to ${ }^{6} \mathrm{~A}_{1} \rightarrow$ ${ }^{4} \mathrm{G}\left(360,375\right.$, and $390 \mathrm{~nm}$ for $\mathrm{Cl}, \mathrm{Br}$, I, respectively) and ${ }^{6} \mathrm{~A}_{1}$ $\rightarrow{ }^{4} \mathrm{D}(450,460$, and $475 \mathrm{~nm})$ transitions. Emission spectra feature only one emission peak (Figure $2 a-c$ ). Generally, the emission and excitation wavelengths of $\mathrm{Mn}$ in such hybrids depend on the ligand field splitting: the energy splitting decreases from $\mathrm{Cl}$ to $\mathrm{I}$, according to spectrochemical series. ${ }^{46}$ The adequate assignment of PLE lines is still rather unrealistic. $^{47}$ To simplify the description of optical properties, we have adopted the difference between the strongest excitation peak around $450 \mathrm{~nm}\left({ }^{6} \mathrm{~A}_{1} \rightarrow{ }^{4} \mathrm{~T}_{2}\right)$ and the emission peak $\left({ }^{4} \mathrm{~T}_{1} \rightarrow{ }^{6} \mathrm{~A}_{1}\right), \mathrm{E}\left[{ }^{4} \mathrm{~T}_{2}\right]-\mathrm{E}\left[{ }^{4} \mathrm{~T}_{1}\right]$ as a measure for the magnitude of the splitting. In this case, larger $\mathrm{E}\left[{ }^{4} \mathrm{~T}_{2}\right]-\mathrm{E}\left[{ }^{4} \mathrm{~T}_{1}\right]$ values correspond to a stronger field. In addition, from lighter to heavier halide, spin-orbit coupling (SOC) gains importance. Figure $2 \mathrm{~d}$ shows how SOC influences the decay time of the emission: $\tau$ is longest in chlorides $(\sim 4 \mathrm{~ms})$ and fastest in iodides $(\sim 40 \mu \mathrm{s})$. In comparison, $\mathrm{Mn}^{2+}$ in a $T_{d}$ oxide environment exhibits radiative lifetimes above $5 \mathrm{~ms}{ }^{48}$ The PLQYs are highest when excited within the lowest energy PLE bands (around $450 \mathrm{~nm}$ ) and decrease from chloride to iodide (Figure 2e). Spectral dependence of PLQY generally follows the PLE spectrum, as expected. However, optical absorption at PLE/PLQY minima is still significant (Figure 8), pointing to the background absorption by nonemissive impurity species such as degradation products (molecular halides, trihalide anions, etc.). Organic-inorganic manganese tetrahalide hybrids can be prepared with a wide variety of cations (Table 1, Table S2). Optical properties of the resulting complexes cover the spectral range between 505 and $547 \mathrm{~nm}$. All of these complexes are bright with PLQYs from $30 \%$ to $90 \%$ (at $450 \mathrm{~nm}$ excitation).
Fully Inorganic Alkali Zinc Halides Doped with Manganese. We have prepared and analyzed Mn-doped zinc halides and several alkali metal zinc halides (Figure 3 ).

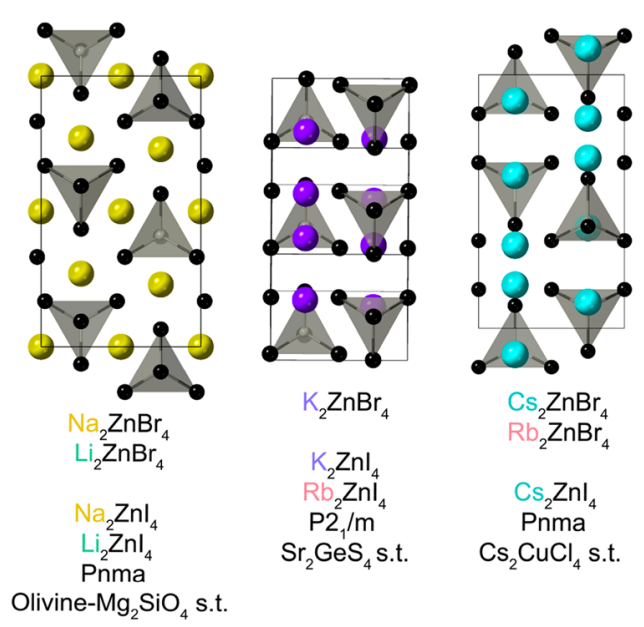

Figure 3. Various crystal structures of $\mathrm{A}_{2} \mathrm{ZnBr}_{4}$, where $\mathrm{A}$ is an alkali metal cation.

They were synthesized by melting the mixtures of the respective metal halides. With $\mathrm{ZnBr}_{2}$ as a host, high $\mathrm{MnBr}_{2}$ loadings of up to $15 \mathrm{wt} \%$ can be achieved without any evidence of multiple phases in powder $\mathrm{X}$-ray diffraction (PXRD, Figure $\mathrm{S} 1$ ). In a $\mathrm{CsBr}-\mathrm{ZnBr}_{2}$ system, all compounds melt congruently, which results in the formation of a pure $\mathrm{Cs}_{2} \mathrm{ZnBr}_{4}$ phase (Figure S2a,b). In the case of $\mathrm{K}_{2} \mathrm{ZnBr}_{4}$ and $\mathrm{Rb}_{2} \mathrm{ZnBr}_{4}$, impurity peaks at small $2 \theta$ might remain unassigned and are attributed to a rather technical purity of the precursors (Figure $\mathrm{S} 2 \mathrm{c}, \mathrm{d}$ ). In $\mathrm{Li}_{2} \mathrm{ZnBr}_{4}$ and $\mathrm{Na}_{2} \mathrm{ZnBr}_{4}$ we have observed identical groups of peaks that belong to unreacted $\mathrm{ZnBr}_{2}$ and $\mathrm{ABr}$ (Figure S2e,f) due to incongruent melting of these ternary phases. ${ }^{49}$ Both $\mathrm{Cs}_{2} \mathrm{ZnI}_{4}$ and $\mathrm{Cs}_{3} \mathrm{ZnI}_{5}$ form as pure phases 

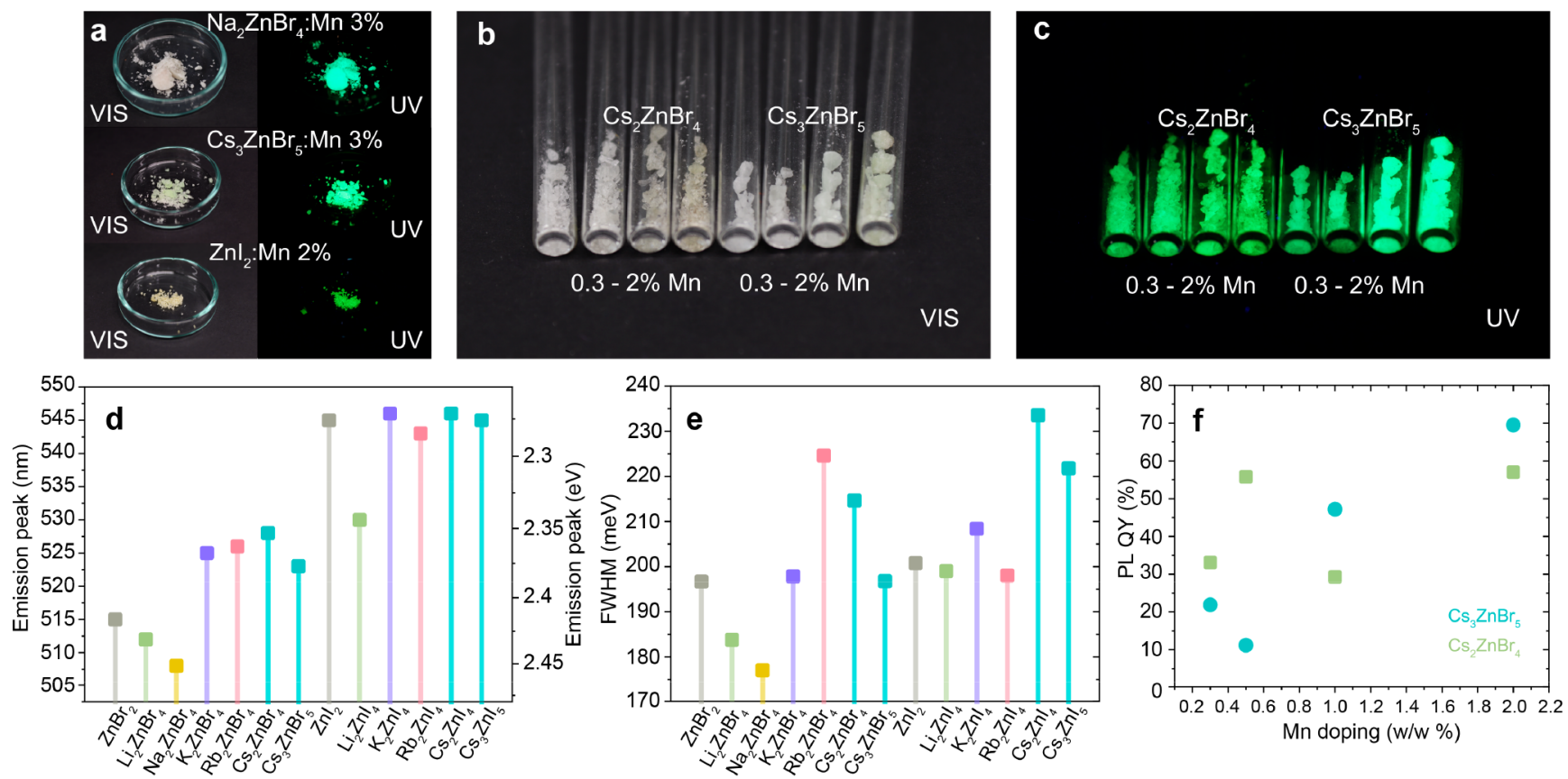

Figure 4. (a) Photograph of various samples under ambient and UV light. (b and c) Photograph of $\mathrm{Cs}_{2} \mathrm{ZnBr}_{4}$ and $\mathrm{Cs}_{3} \mathrm{ZnBr}_{5}$ doped with various $\mathrm{Mn}$ amounts ( $\mathrm{w} / \mathrm{w} \%)$ under visible light and UV excitation $(360 \mathrm{~nm})$. ( $\mathrm{d}$ and e) PL peak position and fwhm of Mn-centered emission in various fully inorganic metal halide hosts (exc. $450 \mathrm{~nm}$ ). (f) PLQY (exc. $450 \mathrm{~nm}$ ) dependence on the $\mathrm{Mn}$ concentration in $\mathrm{Cs}_{2} \mathrm{ZnBr}_{4}$ and $\mathrm{Cs}_{3} \mathrm{ZnBr}_{5}$ demonstrating fast saturation of PLQY values at Mn contents of above $1-2 \%$.

(Figure $\mathrm{S} 3 \mathrm{a}, \mathrm{b}$ ). In the case of $\mathrm{K}_{2} \mathrm{ZnI}_{4}$ and $\mathrm{Rb}_{2} \mathrm{ZnI}_{4}$, unknown impurity phases can be seen (Figure $\mathrm{S} 3 \mathrm{c}, \mathrm{d}$ ). Among olivine structures, only $\mathrm{Li}_{2} \mathrm{ZnI}_{4}$ was obtained as a pure phase (Figure $\mathrm{S} 3 \mathrm{e}$ ) and the formation of $\mathrm{Na}_{2} \mathrm{ZnI}_{4}$ has not been observed; the reaction mixture contained unreacted $\mathrm{NaI}$ and $\mathrm{ZnI}_{2}$ (Figure S3f). All of the doped phosphors exhibit bright characteristic $\mathrm{Mn}$ emission at room temperature, and the deeper color of the doped samples reflects the increase in $\mathrm{Mn}$ concentration (Figure $4 \mathrm{a}-\mathrm{c}$ ).

Mn-containing $\mathrm{ZnBr}_{2}$ and $\mathrm{ZnI}_{2}$ exhibit a bright green emission that peaked at 515 and $545 \mathrm{~nm}$, respectively; with a very similar line broadening (196 and $199 \mathrm{meV}$ ). Ternary halides as hosts allow for tuning the luminescence over a wider region. $\mathrm{A}_{2} \mathrm{ZnBr}_{4}$ crystallize in three distinct crystal structures, stable at room temperature, all with $T_{d}$ symmetry around $\mathrm{Zn}$. $\mathrm{Na}_{2} \mathrm{ZnBr}_{4}$ and $\mathrm{Li}_{2} \mathrm{ZnBr}_{4}$ crystallize in olivine- $\mathrm{Mg}_{2} \mathrm{SiO}_{4}$ orthorhombic structure type, whereas $\mathrm{Cs}_{2} \mathrm{ZnBr}_{4}$ and $\mathrm{Rb}_{2} \mathrm{ZnBr}_{4}$ are isostructural to the $\mathrm{Cs}_{2} \mathrm{CuCl}_{4}$ orthorhombic structure type. $\mathrm{K}_{2} \mathrm{ZnBr}_{4}$ is found in a lower symmetry monoclinic polymorph. In addition, for $\mathrm{Cs}$, another ternary phase exists with $\mathrm{Cs}_{3} \mathrm{ZnBr}_{5}$ stoichiometry, which consists of alternating $\mathrm{Cs} \mathrm{ZnBr}$ and $\mathrm{CsBr}$ layers (Figure 1). In ternary iodides, $\mathrm{Li}_{2} \mathrm{ZnI}_{4}$ and $\mathrm{Na}_{2} \mathrm{ZnI}_{4}$ crystallize in olivine structure, whereas both $\mathrm{K}$ and $\mathrm{Rb}$ homologues exist in monoclinic structure. Only $\mathrm{Cs}_{2} \mathrm{ZnI}_{4}$ has the same structure as its bromide counterpart.

Figure $4 \mathrm{~d}$ and $4 \mathrm{e}$ summarizes the optical properties of the binary and ternary hosts doped with 2 wt \% of $\mathrm{Mn}$. Compounds with olivine structure $\left(\mathrm{Li}_{2} \mathrm{ZnBr}_{4}, \mathrm{Na}_{2} \mathrm{ZnBr}_{4}\right.$, $\mathrm{K}_{2} \mathrm{ZnI}_{4}$ ) systematically show the emission peak shifted toward higher energies: $506-514 \mathrm{~nm}$ for bromides and $530 \mathrm{~nm}$ for iodide. For comparison, $\mathrm{K}, \mathrm{Rb}$, and Cs counterparts emit above $520 \mathrm{~nm}$ (bromides) and above $540 \mathrm{~nm}$ (iodides). Higher peak energies correspond to a stronger ligand field, which is corroborated by sharper PLE peaks. The narrowest fwhm is observed for olivine-type hosts $\left(177 \mathrm{meV}\right.$ for $\mathrm{Na}_{2} \mathrm{ZnBr}_{4}$, Figure 4b). For monoclinic structures $\left(\mathrm{K}_{2} \mathrm{ZnBr}_{4}, \mathrm{~K}_{2} \mathrm{ZnI}_{4}\right.$, and $\left.\mathrm{Rb}_{2} \mathrm{ZnI}_{4}\right)$, the fwhm is is higher $(195-210 \mathrm{meV}) . \mathrm{Cs}_{2} \mathrm{CuCl}_{4}$ type $\mathrm{Rb}_{2} \mathrm{ZnBr}_{4}, \mathrm{Cs}_{2} \mathrm{ZnBr}_{4}$, and $\mathrm{Cs}_{2} \mathrm{ZnI}_{4}$ exhibit the emission with the highest fwhm ranging between 210 and $240 \mathrm{meV}$. Among all cesium-based compounds, the phase with excess cesium halide $\left(\mathrm{Cs}_{3} \mathrm{ZnX}_{5}\right)$ shows narrower emission at a lower wavelength. To test the PLQY dependence on $\mathrm{Mn}$ concentration, we have chosen the compounds in the CsBr$\mathrm{ZnBr}_{2}$ system. From 0.3 to 2 wt \% of $\mathrm{Mn}$, the PLQY increased almost seven times. We have also estimated the equilibrium $\mathrm{Mn}$-halide distances in the host lattice (for the case of $\mathrm{A}_{2} \mathrm{ZnBr}_{4}$ ) using DFT calculations. The calculated distances are summarized in Table 2. Generally, metal-ligand distances are larger in olivine-type structures and shorter in orthorhombic structures.

Table 2. Equilibrium $\mathrm{Mn}-\mathrm{Br}$ distances (Angstroms) Calculated by DFT in Five $\mathrm{A}_{2} \mathrm{ZnBr}_{4}$ Hosts

$\begin{array}{lccccc}\text { compound } & d_{1} & d_{2} & d_{3} & d_{4} & d_{\text {average }} \\ \mathrm{Li}_{2} \mathrm{ZnBr}_{4} & 2.378 & 2.386 & 2.380 & 2.378 & 2.380 \\ \mathrm{Na}_{2} \mathrm{ZnBr}_{4} & 2.383 & 2.381 & 2.383 & 2.384 & 2.383 \\ \mathrm{~K}_{2} \mathrm{ZnBr}_{4} & 2.363 & 2.363 & 2.380 & 2.382 & 2.372 \\ \mathrm{Rb}_{2} \mathrm{ZnBr}_{4} & 2.373 & 2.377 & 2.355 & 2.355 & 2.365 \\ \mathrm{Cs}_{2} \mathrm{ZnBr}_{4} & 2.354 & 2.386 & 2.354 & 2.374 & 2.367\end{array}$

Limitations and Prospects of Mn Green Emission: Decay Rates, PL Peak Position, fwhm, and Absorption Coefficient. Assessment of the practical utility of a novel phosphor for applications such as LCD displays and lighting requires knowledge of the following optical parameters: emission decay rate, PL peak position, fwhm, absorption coefficient, and PLQY. As can be noticed from Figure $2 a-c$, the widths of the excitation and emission bands are notably different: characteristic $\mathrm{Mn}^{2+}$ PLE bands (fwhm $=10-30 \mathrm{~nm}$ ) 
are narrower than the PL band ( $\mathrm{fwhm}=40-60 \mathrm{~nm}$ ). This is often attributed to the difference in the chemical bonding in the ground and excited states. The observable variability in these parameters can be rationalized by considering energy level splittings of the $\mathrm{Mn}^{2+}$ in a tetrahedral halide crystal field, in particular, by focusing on the strength of the crystal field $(\Delta)$ and covalency $(B)$ of the $\mathrm{Mn}$-ligand bond as two primary factors. To illustrate the splitting of the energy states as a function of $\Delta$, a Tanabe-Sugano (TS) correlation diagram is used (Figure 5). The field strength increases from left to right.

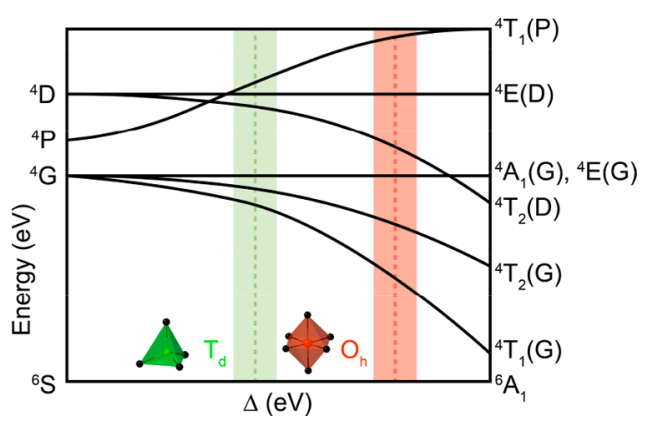

Figure 5. Phenomenological model of the Tanabe-Sugano diagram for a $\mathrm{d}^{5}\left(\mathrm{Mn}^{2+}\right)$ ion. Colored areas show relative locations of tetrahedral and octahedral $\mathrm{Mn}^{2+}$ fields.

On the basis of this general theory of d-ions emission, the strength of the crystal field defines the position of the $\mathrm{Mn}^{2+}$ emission peak: in the weaker field, the ${ }^{4} \mathrm{~T}_{1}$ and ${ }^{6} \mathrm{~A}_{1}$ levels are separated stronger and hence emission occurs at higher energies $(506-520 \mathrm{~nm})$. As the crystal field increases, the emission peak shifts to lower energies $(525-545 \mathrm{~nm})$. The denergy levels are also influenced by the electron-phonon coupling. A general intuition from the TS diagram would be higher slopes shall correspond to greater sensitivity to the electron-phonon coupling and hence higher homogeneous broadening of the transition. This argument fully explains the trends in organic-inorganic chlorides and bromides (Figure 6a). However, in the case of iodide, being the weakest ligand in the halide series, crystal field strength arguments fail to predict correctly the optical properties. Although the experimental splitting between the states still follows the TS diagram (the smallest values of $\mathrm{E}\left[{ }^{4} \mathrm{~T}_{2}\right]-\mathrm{E}\left[{ }^{4} \mathrm{~T}_{1}\right]$ for iodides: $30-32 \mathrm{meV}$ ), the PL peak position shifts to the red and the fwhm is broader (Figure 6a). This can be explained by the Mn-I bond having a more covalent nature and iodine having a higher nephelauxetic effect. "Covalent" in this context refers to the degree of mixing between the $\mathrm{d}$ orbitals of $\mathrm{Mn}$ and orbitals of the ligands. As a result, all energy states in tetraiodomanganates, including those that do not depend on the crystal field splitting, e.g., ${ }^{4} \mathrm{~A}_{1}$, ${ }^{4} E(G),{ }^{4} E(D)$, shift toward lower energies $\left(B^{\prime}<B\right)$. This effect is responsible for tetrahedral $\mathrm{Mn}^{2+}$ orange emission (ca. 575$580 \mathrm{~nm}$ ) in $\mathrm{ZnS}$ host. ${ }^{50}$ In general, the ordering of the ligands in the spectrochemical series and nephelauxetic series is opposite: free ion $<\mathrm{I}^{-}<\mathrm{Br}^{-}<\mathrm{Cl}^{-}<\mathrm{S}^{2-}<\mathrm{F}^{-}<\mathrm{O}^{2-}$ vs free ion $<\mathrm{F}^{-}<\mathrm{O}^{2-}<\mathrm{Cl}^{-}<\mathrm{Br}^{-}<\mathrm{I}^{-}<\mathrm{S}^{2-} .51$ For the case of weak tetrahedral fields, Coloumb repulsion of $\mathrm{d}$ electrons has a higher contribution and the nephelauxetic effect is, therefore, more pronounced. In other words, a more ionic $\mathrm{Mn}$-ligand bonding renders the states involved in the optical transitions more localized on $\mathrm{Mn}$ ions and thus less sensitive to the electron-phonon coupling. This can explain an observation of the narrowest spectral width for $\mathrm{Mn}^{2+} T_{d}$ emission (fwhm =
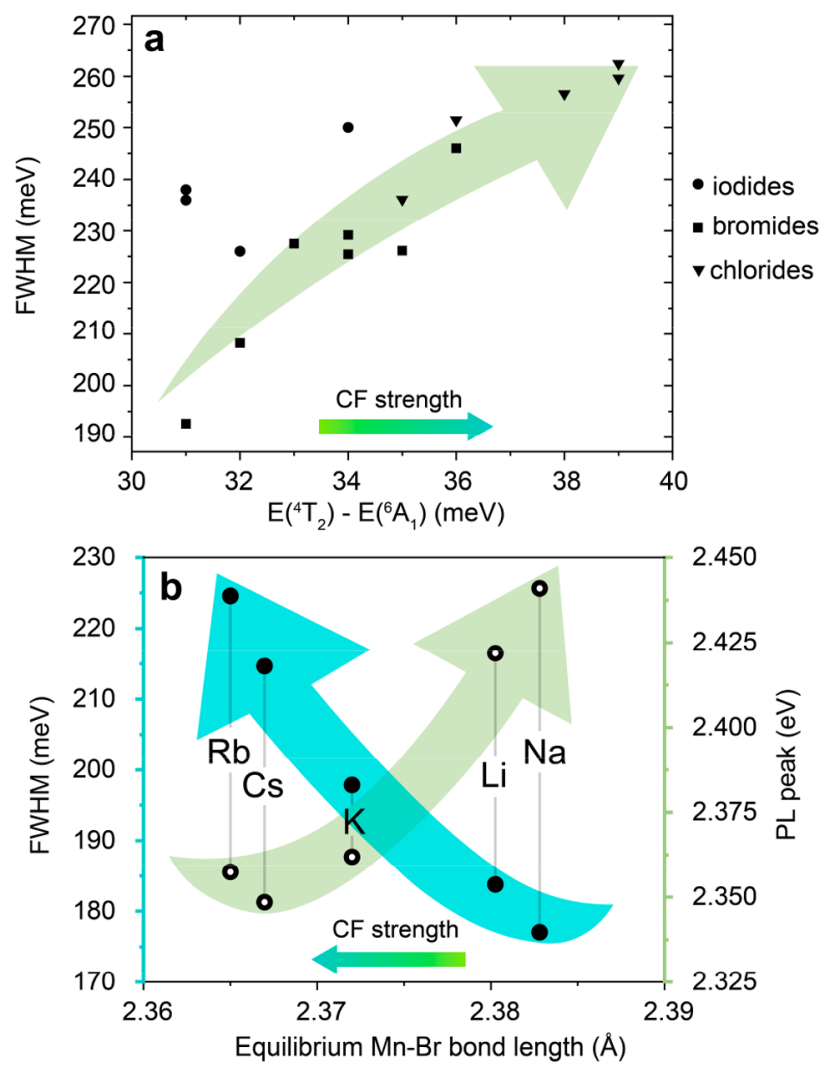

Figure 6. (a) Dependence of the fwhm on the crystal field strength (represented by the difference between optical bands $\mathrm{E}\left[{ }^{4} \mathrm{~T}_{2}\right]$ and $\left.\mathrm{E}\left[{ }^{6} \mathrm{~A}_{1}\right]\right)$ in organic-inorganic hybrid $\mathrm{Mn}(\mathrm{II})$ chlorides, bromides, and iodides. (b) Dependence of the fwhm (shaded circles) and PL (open circles) on the equilibrium $\mathrm{Mn}-\mathrm{Br}$ bond distance in fully inorganic $\mathrm{A}_{2} \mathrm{ZnBr}_{4}$ compounds.

$17.5 \mathrm{~nm}$ ) in the strongest crystal field of oxides. ${ }^{52,53}$ Theoretically, a tetrahedral fluoride environment could result in an even narrower emission line width. However, finding a proper matrix poses a problem: due to the smallest ionic radii of $\mathrm{F}^{-}$among halides ( 1.33 vs $1.81 \AA$ for $\mathrm{Cl}$ ), structures with tetrahedral coordination are scarce. For example, $\mathrm{ZnF}_{2}$ has a rutile structure that features $\mathrm{O}_{h}$ coordination of $\mathrm{Zn}$. The covalency argument also explains why $\mathrm{Mn}^{2+}$ in $T_{d}$ oxide or $\mathrm{Mn}^{4+}$ in $\mathrm{O}_{h}$ fluoride field display longer decay times (few milliseconds) $:{ }^{54}$ higher mixing of states in a more covalent case helps to relax the forbidden nature of the transition.

The nephelauxetic effect is also present in the compounds with the same halide composition (e.g., $\mathrm{A}_{2} \mathrm{ZnBr}_{4}$ ). It has been previously demonstrated from ab initio calculations for a $\mathrm{d}^{3}$ metal impurity in $\mathrm{A}_{2} \mathrm{NaBX}_{6}$ hosts $(\mathrm{A}=\mathrm{K}, \mathrm{Cs}, \mathrm{B}=\mathrm{Sc}, \mathrm{Y})$ that the $B$ parameter and $\Delta$ depend on the metal-ligand distance, which in turn reflects the covalency of the bond. ${ }^{55}$ For $\mathrm{A}_{2} \mathrm{ZnBr}_{4}: \mathrm{Mn}$ compounds, the fwhm and PL peak positions appear to correlate with the average equilibrium $\mathrm{Mn}-\mathrm{Br}$ distance (from Table 2, Figure 6b).

The PL peak position and energy states splitting relate also to the distance between manganese atoms. ${ }^{21,23}$ This can be exemplified by comparing the $\mathrm{Mn}-\mathrm{Mn}$ distance distribution in two compounds: $\mathrm{Bmpip}_{2} \mathrm{MnCl}_{4}$ and $\left(\mathrm{Bz}(\mathrm{Me})_{3} \mathrm{~N}\right)_{2} \mathrm{MnCl}_{4}$ (Figure 7a). In $\left(\mathrm{Bz}(\mathrm{Me})_{3} \mathrm{~N}\right)_{2} \mathrm{MnCl}_{4}$, the smallest $\mathrm{Mn}-\mathrm{Mn}$ distance is $8.5 \AA$, whereas for $\mathrm{Bmpip}_{2} \mathrm{MnCl}_{4}$ it is $9.1 \AA$ (Tables S3 and S4, CCDC 1936177 and CCDC 1936170). The 

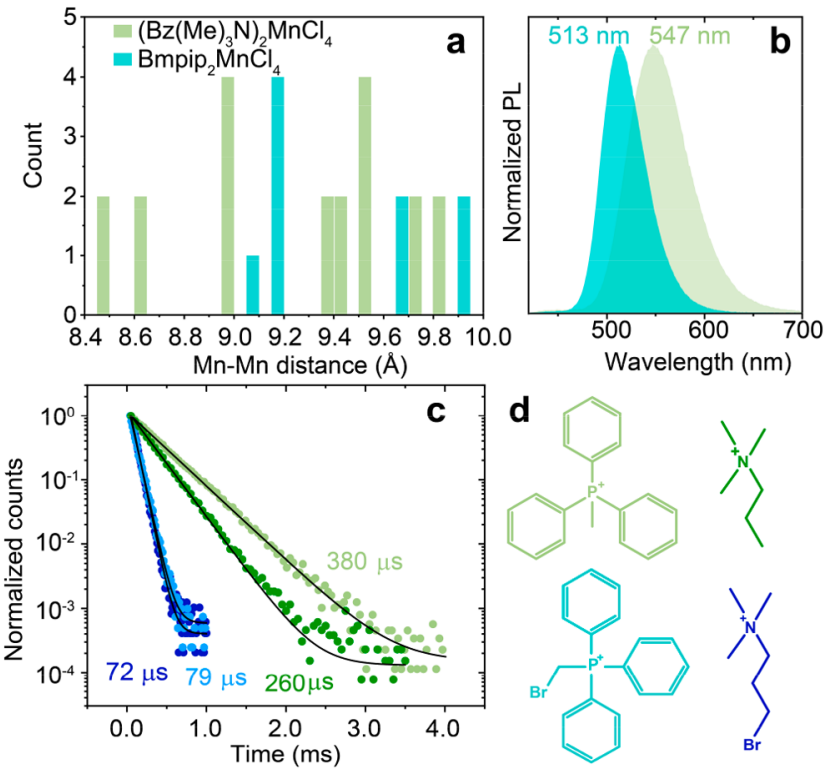

Figure 7. (a) $\mathrm{Mn}-\mathrm{Mn}$ distance distribution in two tetrachloride compounds, $\mathrm{Bz}(\mathrm{Me})_{3} \mathrm{~N}_{2} \mathrm{MnCl}_{4}$ and $\mathrm{Bmpip}_{2} \mathrm{MnCl}_{4}$, calculated from crystal structure files measured with single-crystal X-ray diffraction (CCDC 1936177 and CCDC 1936170). (b) PL spectra (exc. 360 $\mathrm{nm}$ ) of $\mathrm{Bz}(\mathrm{Me})_{3} \mathrm{~N}_{2} \mathrm{MnCl}_{4}$ and $\mathrm{Bmpip}_{2} \mathrm{MnCl}_{4}$. (c) Emission decay for tetraalkylphoshonium, tetraalkylammonium tetrabromomanganates(II) (green), and their bromoalkyl derivatives (blue). (d) Chemical formulas of the cations used for comparison.

emission of $\mathrm{Bmpip}_{2} \mathrm{MnCl}_{4}$ is centered around $513 \mathrm{~nm}$, and the $\mathrm{E}\left[{ }^{4} \mathrm{~T}_{2}\right]-\mathrm{E}\left[{ }^{4} \mathrm{~T}_{1}\right]$ splitting is $38 \mathrm{meV}$. In comparison, a much larger splitting of $51.3 \mathrm{meV}$ in the case of $\left(\mathrm{Bz}(\mathrm{Me})_{3} \mathrm{~N}\right)_{2} \mathrm{MnCl}_{4}$ could originate from the smaller $\mathrm{Mn}-\mathrm{Mn}$ interatomic distance (Figure 7b).

In addition, the larger fwhm of the $547 \mathrm{~nm}$ peak can be attributed to two symmetrically inequivalent $\mathrm{MnCl}_{4}$ units present in the structure.

One of the concerns related to the forbidden nature of the transition is the slower emission decay as compared to, for instance, semiconductor quantum dot phosphors. We have found that tetrabromomangates(II), a bromoalkyl derivative of the cation, expedites decay rates (four times for the case shown in Figure $7 \mathrm{c}$ and $7 \mathrm{~d}$ ). As it has been already discussed, the radiative lifetime decreases from $\mathrm{Cl}$ to $\mathrm{I}$. To control the decay time beyond, we have compared $\left(\mathrm{MePh}_{3} \mathrm{P}\right)_{2} \mathrm{MnBr}_{4}$ and $(n$ $\left.\mathrm{PrMe}_{3} \mathrm{~N}\right)_{2} \mathrm{MnBr}_{4}$ with corresponding analogous compounds where cations are brominated: $\left(\mathrm{BrMePh}_{3} \mathrm{P}\right)_{2} \mathrm{MnBr}_{4}$ and $(n-$ $\left.\mathrm{PrBrMe}_{3} \mathrm{~N}\right)_{2} \mathrm{MnBr}_{4}$. In both cases, we observed a decrease in the emission decay time for the brominated cation from hundreds of microseconds (380 and $260 \mu$ s for phosphonium and ammonium, respectively) to less than $100 \mu \mathrm{s}$ (79 and 72 $\mu \mathrm{s})$. This can be attributed to the proximity of the cation bromine atom to the $\mathrm{Mn}$. In nonhalogenated cations, the shortest $\mathrm{Mn}-\mathrm{Br}$ distance is about $2.5 \AA$ (first coordination sphere of $\mathrm{Mn}$ ), whereas in the halogenated cation, due to the organic cation bromine atom, there is a second $\mathrm{Mn}-\mathrm{Br}$ distance at 4-5 $\AA$ (Table S5, $\left(n-\mathrm{PrBrMe}_{3} \mathrm{~N}\right)_{2} \mathrm{MnBr}_{4}, \mathrm{CCDC}$ 1936114). In the previous study on the exciton decay in $\mathrm{Cat}_{2} \mathrm{MnX}_{4}$, no difference in the decay rate was found for cations comprising heavy atoms, e.g., $\mathrm{Ph}_{4} \mathrm{As}^{+}{ }^{38}$ This could be due to the greater distance between $\mathrm{Mn}$ and As: $6.2 \AA$. This discovery motivates future studies on the structural engineer- ing of faster emission decay by introducing heavy atoms (e.g., iodine, bromine) in the second coordination sphere of $\mathrm{Mn}$.

Another limitation that comes from the forbidden nature of the optical transitions is a relatively low absorption coefficient. To estimate the absorption, we have chosen two organicinorganic hybrid compounds, for which crystals of sufficient quality and size $(4-7 \mathrm{~mm})$ could be isolated: (Bz$\left.(\mathrm{Me})_{3} \mathrm{~N}\right)_{2} \mathrm{MnBr}_{4}$ and $\left(\mathrm{Bz}(\mathrm{Me})_{3} \mathrm{~N}\right)_{2} \mathrm{MnI}_{4}$. Light absorption was deduced from the transmission spectra by subtracting the reflectivity. By dividing the spectral optical depth $\tau_{\lambda}$ (at $450 \mathrm{~nm}$ for bromide and $475 \mathrm{~nm}$ for iodide) by the dimension of the crystal, we obtained the directional attenuation coefficient $\mu_{\lambda}$ (Figure $8 \mathrm{a}$ and $8 \mathrm{~b}$ ): $0.5 \mathrm{~cm}^{-1}$ for bromide and $55 \mathrm{~cm}^{-1}(128$
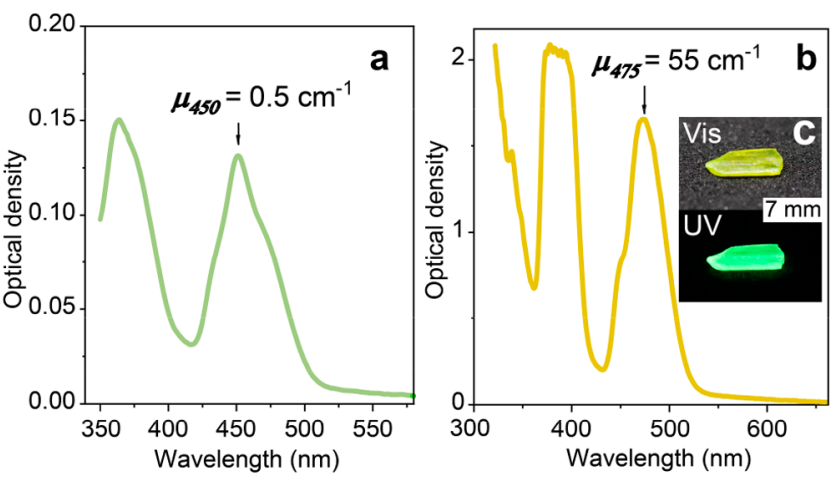

Figure 8. Absorption spectra and spectral absorption coefficients of (a) $\left.\mathrm{Bz}(\mathrm{Me})_{3} \mathrm{~N}\right)_{2} \mathrm{MnBr}_{4}$ and (b) $\left(\mathrm{Bz}(\mathrm{Me})_{3} \mathrm{~N}\right)_{2} \mathrm{MnI}_{4}$. (c) Photo of the $\left(\mathrm{Bz}(\mathrm{Me})_{3} \mathrm{~N}\right)_{2} \mathrm{MnI}_{4}$ crystal under $\mathrm{UV}$ and daylight.

$\mathrm{cm}^{-1} \mathrm{M}^{-1}$ ) for iodide. A higher absorption coefficient correlates well with the faster emission in iodides. However, these values are still very low when compared to the organic dyes (e.g., fluorescein, $\lambda_{500}=92230 \mathrm{~cm}^{-1} \cdot \mathrm{M}^{-1}$ ) ${ }^{56}$ or direct band-gap semiconductors (e.g., InP, $\lambda_{400}=30861 \mathrm{~cm}^{-1}$ ). ${ }^{57}$

\section{CONCLUSIONS}

We prepared and summarized the properties of various halides with tetrahedral coordination of $\mathrm{Mn}(\mathrm{II})$ : organic-inorganic manganese(II) tetrahalide hybrids and $\mathrm{Mn}$ (II)-doped fully inorganic ternary halides. Thus far, research efforts around Mnbased green emitters for display and lighting applications have focused on oxide matrixes. A concerted effort is urgently needed for unveiling the potential $\mathrm{Mn}$ (II) in solid-state halides. The tetrahedral halide ligand environment, in particular, iodide and bromide, brings about its advantages over oxides: faster emission decay of $0.05-0.5 \mathrm{~ms}$ (vs $4-7 \mathrm{~ms}$ in oxides or oxynitrides), larger PLQY of up to $90 \%$, and facile lowtemperature synthesis (vs $1000-1500{ }^{\circ} \mathrm{C}$ for oxides). Emission and excitation spectra can be fine tuned by the crystal field splitting parameters. The latter are adjustable by both the halide composition as well as the distance between manganese atoms. The emission decay is accelerated by four times in organic-inorganic hybrids with the additional halide atom in the second coordination sphere of $\mathrm{Mn}$. We propose that the two effects, namely, crystal field strength and nephelauxetic effect, compete in the $\mathrm{Cl}, \mathrm{Br}$, and I series and have opposite trends: the PL broadening and red shift in the case of $\mathrm{Cl}$ originates from strong crystal field splitting, whereas the same effect in I is attributed to the higher covalency of the $\mathrm{Mn}-\mathrm{I}$ bond. The entirety of the experimental results on the structure-property relationship allows drawing the following 
conclusions as to how engineerable the PL characteristics can be. In particular, weaker fields and less covalent $\mathrm{Mn}$-ligand bonds cause emission that is narrower yet slower $(5-10 \mathrm{~ms})$ and less efficient. The major practical hurdle for this class of phopshors concerns low absorption in the blue region due to the forbidden nature of the transition (Laporte rule). Overcoming this limitation requires new materials design strategies, which may include sensitization or enhancement of the SOC effect.

\section{ASSOCIATED CONTENT}

\section{S Supporting Information}

The Supporting Information is available free of charge at https://pubs.acs.org/doi/10.1021/acs.chemmater.9b03782.

Crystallographic data for $\left(\mathrm{Bz}(\mathrm{Me})_{3} \mathrm{~N}\right)_{2} \mathrm{MnCl}_{4}$ (CCDC 1936177) (CIF)

Crystallographic data for $\left(\mathrm{Bz}(\mathrm{Me})_{3} \mathrm{~N}\right)_{2} \mathrm{MnI}_{4}$ (CCDC 1936176) (CIF)

Crystallographic data for $\mathrm{Bmpip}_{2} \mathrm{MnCl}_{4}$ (CCDC 1936170) (CIF)

Crystallographic data for $\left(n-\mathrm{PrBrMe}_{3} \mathrm{~N}\right)_{2} \mathrm{MnBr}_{4}(\mathrm{CCDC}$ 1936114) (CIF)

Materials; Energy levels for $\mathrm{Mn}^{2+}$ in tetrahedral halide environment; photoluminescence quantum yield $(\Phi)$, total life-time $\tau_{\text {tot, }}$ and radiative life-time $\tau_{\mathrm{r}}$, calculated according to the formula $\tau_{\mathrm{r}}=\tau_{\text {tot }} / \Phi$, for several organic-inorganic hybrid manganese halides; XRD patterns of $\mathrm{ZnBr}_{2}$ with different $\mathrm{Mn}$ mass loading (\%) demonstrating that up to $15 \%$ of $\mathrm{Mn}(\mathrm{II})$ can be accommodated without additional phases appearing, and close-up of the (224) diffraction peak of $\mathrm{ZnBr}_{2}$ depicting a very small shift corresponding to the increase of the unit cell size due to $\mathrm{Mn}$ incorporation; measured and simulated XRD patterns for ternary alkali zinc bromides with $2 \% \mathrm{Mn}$ mass loading; measured and simulated XRD patterns for ternary alkali zinc iodides with $2 \% \mathrm{Mn}$ mass loading; crystal data and structure refinement for $\left(\mathrm{Bz}(\mathrm{Me})_{3} \mathrm{~N}\right)_{2} \mathrm{MnCl}_{4}$; crystal data and structure refinement for $\mathrm{Bmpip}_{2} \mathrm{MnCl}_{4}$; crystal data and structure refinement for $\left(n-\mathrm{PrBrMe}_{3} \mathrm{~N}\right)_{2} \mathrm{MnBr}_{4}$; crystal data and structure refinement for $\left(\mathrm{Bz}(\mathrm{Me})_{3} \mathrm{~N}\right)_{2} \mathrm{MnI}_{4}$; melting points of fully inorganic tertiary zinc halides (PDF)

\section{AUTHOR INFORMATION}

\section{Corresponding Author}

*E-mail: mvkovalenko@ethz.ch.

\section{ORCID}

Yevhen Shynkarenko: 0000-0002-1587-1752

Sergii Yakunin: 0000-0002-6409-0565

Maksym V. Kovalenko: 0000-0002-6396-8938

\section{Notes}

The authors declare no competing financial interest.

\section{ACKNOWLEDGMENTS}

The authors are indebted to Dr. Stefan Ochsenbein and Bogdan Benin for helpful discussions. This work was financially supported by the European Union through Horizon 2020 research and innovation programme (grant agreement No. 819740, project SCALE-HALO)

\section{REFERENCES}

(1) Smets, B. M. J. Phosphors Based on Rare-Earths, a New Era in Fluorescent Lighting. Mater. Chem. Phys. 1987, 16 (3-4), 283-299.

(2) Chen, H. W.; Lee, J. H.; Lin, B. Y.; Chen, S.; Wu, S. T. Liquid Crystal Display and Organic Light-Emitting Diode Display: Present Status and Future Perspectives. Light: Sci. Appl. 2018, 7 (3), 1716817168.

(3) Zutic, I.; Fabian, J.; Das Sarma, S. Spintronics: Fundamentals and Applications. Rev. Mod. Phys. 2004, 76 (2), 323-410.

(4) Loutts, G. B.; Warren, M.; Taylor, L.; Rakhimov, R. R.; Ries, H. R.; Miller, G.; Noginov, M. A.; Curley, M.; Noginova, N.; Kukhtarev, N.; Caulfield, H. J.; Venkateswarlu, P. Manganese-Doped Yttrium Orthoaluminate: A Potential Material for Holographic Recording and Data Storage. Phys. Rev. B: Condens. Matter Mater. Phys. 1998, 57 (7), 3706-3709.

(5) Zhydachevskii, Y.; Suchocki, A.; Berkowski, M.; Zakharko, Y. Optically Stimulated Luminescence of $\mathrm{YAlO}_{3}: \mathrm{Mn}^{2+}$ for Radiation Dosimetry. Radiat. Meas. 2007, 42 (4-5), 625-627.

(6) Pust, P.; Schmidt, P. J.; Schnick, W. A Revolution in Lighting. Nat. Mater. 2015, 14 (5), 454-458.

(7) Valizadeh, A.; Mussa Farkhani, S. Review: Three Synthesis Methods of CdX (X = Se, S or Te) Quantum Dots. IET Nanobiotechnol. 2014, 8 (2), 59-76.

(8) Rzigalinski, B. A.; Strobl, J. S. Cadmium-Containing Nanoparticles: Perspectives on Pharmacology and Toxicology of Quantum dots. Toxicol. Appl. Pharmacol. 2009, 238 (3), 280-288.

(9) Protesescu, L.; Yakunin, S.; Bodnarchuk, M. I.; Krieg, F.; Caputo, R.; Hendon, C. H.; Yang, R. X.; Walsh, A.; Kovalenko, M. V. Nanocrystals of cesium lead halide perovskites $\left(\mathrm{CsPbX}_{3}, \mathrm{X}=\mathrm{Cl}, \mathrm{Br}\right.$, and I): novel optoelectronic materials showing bright emission with wide color gamut. Nano Lett. 2015, 15 (6), 3692-3696.

(10) Verma, S.; Verma, K.; Kumar, D.; Chaudhary, B.; Som, S.; Sharma, V.; Kumar, V.; Swart, H. C. Recent Advances in Rare Earth Doped Alkali-Alkaline Earth Borates for Solid State Lighting Applications. Phys. B 2018, 535, 106-113.

(11) Li, S.; Wang, L.; Tang, D.; Cho, Y.; Liu, X.; Zhou, X.; Lu, L.; Zhang, L.; Takeda, T.; Hirosaki, N.; Xie, R.-J. Achieving high quantum efficiency narrow-band $\beta$-Sialon:Eu ${ }^{2+}$ Phosphors for highbrightness LCD backlights by reducing the $\mathrm{Eu}^{3+}$ Luminescence Killer. Chem. Mater. 2018, 30 (2), 494-505.

(12) Zhao, M.; Liao, H.; Ning, L.; Zhang, Q.; Liu, Q.; Xia, Z. Nextgeneration narrow-band green-emitting $\mathrm{RbLi}\left(\mathrm{Li}_{3} \mathrm{SiO}_{4}\right)_{2}: \mathrm{Eu}^{2+}$ phosphor for backlight display application. Adv. Mater. 2018, 30 (38), 1802489.

(13) Zhao, M.; Zhou, Y.; Molokeev, M. S.; Zhang, Q.; Liu, Q.; Xia, $\mathrm{Z}$. Discovery of new narrow-band phosphors with the $\mathrm{UCr}_{4} \mathrm{C}_{4}$-related type structure by alkali cation effect. Adv. Opt. Mater. 2019, 7 (6), 1801631.

(14) Li, Y. M.; Qi, S.; Li, P. L.; Wang, Z. J. Research Progress of Mn Doped Phosphors. RSC Adv. 2017, 7 (61), 38318-38334.

(15) Zhou, Q.; Dolgov, L.; Srivastava, A. M.; Zhou, L.; Wang, Z. L.; Shi, J. X.; Dramicanin, M. D.; Brik, M. G.; Wu, M. M. $\mathrm{Mn}^{2+}$ and $\mathrm{Mn}^{4+}$ Red Phosphors: Synthesis, Luminescence and Applications in WLEDs. A Review. J. Mater. Chem. C 2018, 6 (11), 2652-2671.

(16) Yeo, B. E.; Cho, Y. S.; Huh, Y. D. Synthesis and Photoluminescence Properties of a Red-Emitting Phosphor, $\mathrm{K}_{2} \mathrm{SiF}_{6}: \mathrm{Mn}^{4+}$, for Use in Three-Band White LED Applications. Opt. Mater. 2016, 51, 50-55.

(17) Zhu, Y. L.; Liang, Y. J.; Liu, S. Q.; Li, H. R.; Chen, J. H. Narrow-Band Green-Emitting $\mathrm{Sr}_{2} \mathrm{MgAl}_{22} \mathrm{O}_{36}: \mathrm{Mn}_{2+}$ Phosphors with Superior Thermal Stability and Wide Color Gamut for Backlighting Display Applications. Adv. Opt. Mater. 2019, 7 (6), 18014191801428.

(18) Song, E. H.; Zhou, Y. Y.; Wei, Y.; Han, X. X.; Tao, Z. R.; Qiu, R. L.; Xia, Z. G.; Zhang, Q. Y. A thermally stable narrow-band greenemitting phosphor $\mathrm{MgAl}_{2} \mathrm{O} 4: \mathrm{Mn}^{2+}$ for wide color gamut backlight display application. J. Mater. Chem. C 2019, 7 (27), 8192-8198.

(19) Linwood, S. H.; Weyl, W. A. The Fluorescence of Manganese in Glasses and Crystals. J. Opt. Soc. Am. 1942, 32 (8), 443-453. 
(20) Cotton, F. A.; Goodgame, M.; Goodgame, D. M. Absorption Spectra and Electronic Structures of Some Tetrahedral Manganese(II) Complexes. J. Am. Chem. Soc. 1962, 84 (2), 167-171.

(21) Rodriguez-Lazcano, Y.; Nataf, L.; Rodriguez, F. Electronic Structure and Luminescence of $\left[\left(\mathrm{CH}_{3}\right)_{4} \mathrm{~N}\right]_{2} \mathrm{MnX}_{4}(\mathrm{X}=\mathrm{Cl}, \mathrm{Br})$ Crystals at High Pressures by Time-Resolved Spectroscopy: Pressure Effects on the Mn-Mn Exchange Coupling. Phys. Rev. B: Condens. Matter Mater. Phys. 2009, 80 (8), 5115-5125.

(22) Tanabe, Y.; Sugano, S. On the Absorption Spectra of Complex Ions. J. Phys. Soc. Jpn. 1954, 9 (5), 766-779.

(23) Bai, X. W.; Zhong, H. Z.; Chen, B. K.; Chen, C.; Han, J. B.; Zeng, R. S.; Zou, B. S. Pyridine-Modulated Mn Ion Emission Properties of $\mathrm{C}_{10} \mathrm{H}_{12} \mathrm{~N}_{2} \mathrm{MnBr}_{4}$ and $\mathrm{C}_{5} \mathrm{H}_{6} \mathrm{NMnBr}_{3}$ Single Crystals. J. Phys. Chem. C 2018, 122 (5), 3130-3137.

(24) Li, M. Z.; Zhou, J.; Molokeev, M. S.; Jiang, X. X.; Lin, Z. S.; Zhao, J.; Xia, Z. G. Lead-Free Hybrid Metal Halides with a GreenEmissive $\left[\mathrm{MnBr}_{4}\right]$ Unit as a Selective Turn-On Fluorescent Sensor for Acetone. Inorg. Chem. 2019, 58 (19), 13464-13470.

(25) Xu, L. J.; Sun, C. Z.; Xiao, H.; Wu, Y.; Chen, Z. N. GreenLight-Emitting Diodes based on Tetrabromide Manganese(II) Complex through Solution Process. Adv. Mater. 2017, 29 (10), 1605739-1605744.

(26) Qin, Y. Y.; Tao, P.; Gao, L.; She, P. F.; Liu, S. J.; Li, X. L.; Li, F. Y.; Wang, H.; Zhao, Q.; Miao, Y. Q.; Huang, W. Designing Highly Efficient Phosphorescent Neutral Tetrahedral Manganese(II) Complexes for Organic Light-Emitting Diodes. Adv. Opt. Mater. 2019, 7 (2), 1801160-1801167.

(27) Cotton, F. A.; Daniels, L. M.; Huang, P. L. Correlation of Structure and Triboluminescence for Tetrahedral Manganese(II) Compounds. Inorg. Chem. 2001, 40 (14), 3576-3578.

(28) Micic, R.; Draskovic, B. Some Photoluminescence Properties of $\mathrm{Mn}^{2+}$ in Magnesium Bromide. Phys. Status Solidi B 1985, 128 (2), 489-494.

(29) Kovaleva, I. S.; Kuznetsova, I. Y.; Fedorov, V. A. Phase Relationships in the CsBr-MBr $(\mathrm{M}=\mathrm{Zn}, \mathrm{Cd}, \mathrm{Hg})$ Systems. Inorg. Mater. 1995, 31 (12), 1442-1446.

(30) Pfitzner, A.; Crockcroft, J. K.; Solinas, I.; Lutz, H. D. New Halogenozincates $\mathrm{M}_{2} \mathrm{ZnX}_{4}(\mathrm{M}(\mathrm{I})=\mathrm{Li}, \mathrm{Na}, \mathrm{X}=\mathrm{Cl}, \mathrm{Br})$ of Olivine Type. Z. Anorg. Allg. Chem. 1993, 619 (6), 993-998.

(31) Lutz, H. D.; Pfitzner, A. $\mathrm{Li}_{2} \mathrm{ZnI}_{4}$, the First Olivine Type Iodide. Z. Naturforsch., B: J. Chem. Sci. 1989, 44 (9), 1047-1049.

(32) Sawada, S.; Shiroishi, Y.; Yamamoto, A.; Takashige, M.; Matsuo, M. Ferroelectricity in $\mathrm{Rb}_{2} \mathrm{ZnBr}_{4}$. J. Phys. Soc. Jpn. 1977, 43 (6), 2101-2102.

(33) Kasano, H.; Tsuchiyama, S.; Mashiyama, H. Phase Transitions in $\mathrm{A}_{2} \mathrm{BX}_{4}$-Type Crystals with $\mathrm{Sr}_{2} \mathrm{GeS}_{4}$-Type Structure. J. Korean Phys. Soc. 1998, 32, 53-55.

(34) Shimizu, F.; Yamaguchi, T.; Suzuki, H.; Takashige, M.; Sawada, S. New Ferroelectric $\mathrm{K}_{2} \mathrm{ZnBr}_{4}$. J. Phys. Soc. Jpn. 1990, 59 (6), 19361939.

(35) Shimizu, F.; Yamaguchi, T.; Takashige, M. Phase Transitions of the Mixed System of $\left(\mathrm{Rb}_{1-\mathrm{x}} \mathrm{Cs}_{\mathrm{x}}\right)_{2} \mathrm{ZnI}_{4}$. Ferroelectrics 2006, 337, 12491256.

(36) Shimizu, F.; Anzai, T.; Sekiguchi, H.; Takashige, M.; Sawada, S. Ferroelectricity in $\mathrm{K}_{2} \mathrm{ZnI}_{4}$. J. Phys. Soc. Jpn. 1994, 63 (2), 437-440.

(37) Shimizu, F.; Takashige, M. Phase Transitions in the Solid Solution $\mathrm{K}_{2} \mathrm{ZnI}_{4}-\mathrm{Rb}_{2} \mathrm{ZnI}_{4}$. J. Korean Phys. Soc. 1996, 29, 460-463.

(38) Wrighton, M.; Ginley, D. Excited-State Decay of Tetrahalomanganese(II) Complexes. Chem. Phys. 1974, 4 (2), 295299.

(39) Heming, M.; Lehmann, G.; Henkel, G.; Krebs, B. Correlation of Zero-Field Splittings and Site Distortions. 3. $\mathrm{MnBr}_{4}{ }^{2-}$ and CrystalStructure Refinements for $\mathrm{Rb}_{3} \mathrm{ZnBr}_{5}$ and $\mathrm{Cs}_{2} \mathrm{ZnBr}_{4}$. Z. Naturforsch., A: Phys. Sci. 1981, 36 (3), 286-293.

(40) Su, B.; Molokeev, M. S.; Xia, Z. $\mathrm{Mn}^{2}$-Based Narrow-Band Green-Emitting $\mathrm{Cs}_{3} \mathrm{MnBr}_{5}$ Phosphor and the Performance Optimization by $\mathrm{Zn}^{2+}$ Alloying. J. Mater. Chem. C 2019, 7, 11220-11226.

(41) Sheldrick, G. M. Crystal Structure Refinement with SHELXL. Acta Crystallogr., Sect. C: Struct. Chem. 2015, 71, 3-8.
(42) Dolomanov, O. V.; Bourhis, L. J.; Gildea, R. J.; Howard, J. A. K.; Puschmann, H. OLEX2: a Complete Structure Solution, Refinement and Analysis Program. J. Appl. Crystallogr. 2009, 42, 339-341.

(43) Kresse, G.; Furthmuller, J. Efficient Iterative Schemes for Abinitio Total-Energy Calculations Using a Plane-Wave Basis Set. Phys. Rev. B: Condens. Matter Mater. Phys. 1996, 54 (16), 11169-11186.

(44) Perdew, J. P.; Burke, K.; Ernzerhof, M. Generalized Gradient Approximation Made Simple. Phys. Rev. Lett. 1997, 78 (7), 13961396.

(45) Blochl, P. E. Projector Augmented-Wave Method. Phys. Rev. B: Condens. Matter Mater. Phys. 1994, 50 (24), 17953-17979.

(46) Buric, I.; Nikolic, K.; Aleksic, A. Effect of Ligand-Field on Excitation Luminescence Spectra of Some Complex-Compounds of Manganese (II). Czech. J. Phys. 1977, 27 (5), 583-594.

(47) Buric, I.; Nikolic, K.; Aleksic, A. Excitation-Spectra of Tetrahedral Complex-Compounds of Manganese(II) Bromide with Hydrobromides of Some Derivatives of Pyridine and Pyperidine. Czech. J. Phys. 1977, 27 (2), 224-232.

(48) Xu, X. Q.; Ren, J.; Huang, N.; Zeng, H. D.; Chen, G. R.; Kong, D. S.; Gu, C. J.; Chen, C. M.; Liu, Z. B.; Kong, L. R.; Tao, H. Z. Broadly tunable emission from Mn-doped zinc gallogermanate phosphors through composition modification. Opt. Mater. Express 2014, 4 (11), 2433-2440.

(49) Romero-Serrano, A.; Hernandez-Ramirez, A.; Cruz-Ramirez, A.; Hallen-Lopez, M.; Zeifert, B. Optimization and Calculation of the $\mathrm{MCl}-\mathrm{ZnCl}_{2}(\mathrm{M}=\mathrm{Li}, \mathrm{Na}, \mathrm{K})$ Phase Diagrams. Thermochim. Acta 2010, $510(1-2), 88-92$.

(50) Mehra, A. Energy Levels of Divalent Manganese in ZnS. J. Electrochem. Soc. 1971, 118 (1), 136-140.

(51) Newman, D. J. Ligand Ordering Parameters. Aust. J. Phys. 1977, 30 (3), 315-323.

(52) Nagura, T.; Kominami, H.; Nakanishi, Y.; Hara, K. Investigation of the Fabrication Parameters Affecting the Cathodoluminescence Property of $\mathrm{ZnAl}_{2} \mathrm{O}_{4}: \mathrm{Mn}$ Green Phosphors. Jpn. J. Appl. Phys. 2009, 48 (9), 2302-2324.

(53) Kim, J. S.; Lee, S. G.; Park, H. L.; Park, J. Y.; Han, S. D. Optical and Electrical Properties of $\mathrm{ZnGa}_{2} \mathrm{O}_{4}: \mathrm{Mn}^{2+}$ Powder Electroluminescent Device. Mater. Lett. 2004, 58 (7-8), 1354-1357.

(54) Sijbom, H. F.; Joos, J. J.; Martin, L. I. D. J.; Van den Eeckhout, K.; Poelman, D.; Smet, P. F. Luminescent Behavior of the $\mathrm{K}_{2} \mathrm{SiF}_{6}: \mathrm{Mn}^{4+}$ Red Phosphor at High Fluxes and at the Microscopic Level. ECS J. Solid State Sci. Technol. 2016, 5 (1), R3040-R3048.

(55) Trueba, A.; Garcia-Fernandez, P.; Garcia-Lastra, J. M.; Aramburu, J. A.; Barriuso, M. T.; Moreno, M. Spectrochemical Series and the Dependence of Racah and 10Dq Parameters on the MetalLigand Distance: Microscopic Origin. J. Phys. Chem. A 2011, 115 (8), $1423-1432$.

(56) Seybold, P. G.; Gouterman, M.; Callis, J. Calorimetric Photometric and Lifetime Determinations of Fluorescence Yields of Fluorescein Dyes. Photochem. Photobiol. 1969, 9 (3), 229-242.

(57) Aspnes, D. E.; Studna, A. A. Dielectric Functions and OpticalParameters of $\mathrm{Si}, \mathrm{Ge}, \mathrm{GaP}, \mathrm{GaAs}, \mathrm{GaSb}$, InP, InAs, and InSb from 1.5 to $6.0 \mathrm{eV}$. Phys. Rev. B: Condens. Matter Mater. Phys. 1983, 27 (2), 985-1009. 